\title{
Linking relief, rehabilitation and development (LRRD): lessons learned from the Australian and the Canadian Red Cross waste management program in the Maldives
}

\author{
W. Pramana \\ International Operations of Canadian Red Cross, Canada
}

\begin{abstract}
In response to the 2004 tsunami, the Australian and the Canadian Red Cross societies, and the Canadian International Development Agency collaborated with the Government of the Maldives (GoM) in the Tsunami Debris and Waste Management Program (2005-2007). It aimed to address relief, recovery and development issues: (a) the widespread and unmanaged waste left by the tsunami and accumulation of household waste, and (b) the lack of sustainable island waste-management practices prior to the tsunami. This paper analyses the approaches used in the program in terms of linking relief, rehabilitation and development (LRRD) and lessons on appropriate approaches to be considered in a context where issues about government versus community responsibility are a critical component.

The program demonstrates that it is possible to create changes in community awareness, knowledge and practices on waste management in 74 islands in a short period of time (2005-2007). Additionally, the program became a catalyst for formulation of the government policy on waste management and for establishment of a better accountability mechanism with island communities. It further facilitated waste management communication between island and atoll offices.

Based on the good practices and lessons learned from the program, ensuring sustainable changes involves (a) an adequate capacity assessment of the community and local institutions in both the design phase of the community intervention and the exit strategy, (b) integration of a strong and comprehensive community self-reliance intervention in the recovery program, (c) being rigorous
\end{abstract}


in undertaking a risk assessment of potential implementing partners and in selecting relevant measures to mitigate the likelihood that they are unable to fully deliver on their commitments; and (d) close monitoring of progress, in terms of results achievement, particularly where the context and key factors to a success are not fully understood at the outset and/or are fluid.

Keywords: solid waste management, linking relief, rehabilitation and development (LRRD), exit strategy, community self-reliance.

\section{LRRD conceptual framework}

The concept of linking relief, rehabilitation and development (LRRD) as an operational philosophy has been around since the 1970s in the form of the continuum model (or linear sequence) and in the 1990s in the form of the contiguum model [1]. The basic tenet of LRRD is that humanitarian relief, recovery and development assistance should be structured in a way that reduces the need for humanitarian assistance and promotes development objectives before, during and after emergencies. The continuum model holds that the development impact must be considered from the pre-disaster through the emergency stages and on to the rehabilitation or early recovery and the reconstruction or recovery phases. The contiguum model reflects the fact that different response needs and phases might co-exist simultaneously.

Recently, Buttner [2] questioned the utility of the contiguum model particularly in terms of its application to protracted conflicts and situations in which the lack or incapacity of local authorities may hamper the implementation of recovery or early development assistance. He stresses the importance of considering the "context specific" situation in understanding the best practices for promoting LRRD.

Several LRRD approaches and practices are employed by international development organizations; however, irrespective of the different models $[1,3]$ : they are (a) building and sustaining the capacities of local systems and institutions; (b) addressing underlying vulnerabilities; (c) mainstreaming disaster -risk reduction strategies, including preparedness; (d) applying rights-based approaches; (e) working with local partners and people, including the use of participatory approaches; (f) defining exit strategies; and (g) using a livelihood framework.

This paper analyses the LRRD approaches and practices used in the waste management program and lessons learned in terms of appropriate approaches to be adopted in a similar context.

\section{Maldives: socio-political background}

\subsection{Political background, institutional capacity of civil service and community participation}

The Republic of Maldives was founded through the 1968 referendum [4]. Since then there have been three Presidents. The current President is Mohamed 
Nasheed (2008 - present). The Maldives have experienced major turmoil causing political instability from 1988 to unprecedented anti-government demonstrations calling for political reforms in 2005 [5]. A new constitution was ratified in August 2008, paving the way for the country's first multi-party presidential election two months later.

With its population of just over 300,000 and a per capita GDP approaching US \$2800, the Maldives is on its way to becoming a middle-income country; however, the GoM's institutional capacity lags behind that of an average uppermiddle income country [6]. At the inception of the project, the Maldivian civil services needed to strengthen policies, implementation and administrative capabilities, and effective performance management strategies, including transparency. The capacities of local authorities were similarly limited. The newly-appointed island councillors often lacked adequate knowledge and experience in terms of the island's governance systems or even in governing an island community [7].

Despite the limited institutional capacities, the communities on most of the islands expected the government to provide and pay for basic services, including waste management; hence, community contributions to service development was often limited [6, 7]. A vulnerabilities and capacities assessment, undertaken by the International Federation of the Red Cross and Red Crescent's CommunityBased Disaster Management program concluded that, in general, Maldivian communities had not been exposed to participatory methods and programs as part of service development [8]. Consequently, communities were generally not proactive in solving service-related problems, nor did they employ self-help or community-centred approaches.

\section{Tsunami debris and the waste management program}

\subsection{Waste management issues, pre- and post-tsunami}

The United Nations Environment Program (UNEP) estimated that the tsunami had created approximately 290,000 cubic meters (m3) of debris and waste in the Maldives, adding to some $50,000 \mathrm{~m}^{3}$ of pre-existing household and other waste [8]. The average rate of solid waste generation in the capital and largest city, Malé, was $0.8-1 \mathrm{~kg} /$ person/day and in the atolls $0.3-0.5 \mathrm{~kg} /$ person/day; fewer than $2 \%$ of the islands imposed a fee-for-service waste management system [9]. Prior to the tsunami, disposal sites, often located along vegetation lines and shorelines, were seldom controlled or even managed [6].

\subsection{The first phase and initial program design}

The first phase of the Program, which ran from May 2005 to June 2007 was known by CRC as 'Phase 1' implemented jointly by ARC and CRC, The Community-Based Waste Management project was known by $\mathrm{CRC}$ as 'Phase 2' and was implemented by CRC from March 2008 to June 2009. The first phase consisted of both relief (component \#1) and recovery (component \#2 and \#3) [8]. 
Component \#1 on tsunami debris and waste cleanup is relief activity, focusing on removal and transfer of all visible, non-reusable waste (tsunami and domestic) from the land surface of the 74 designated islands to the existing principal landfill island of Thila Fushi. Component \#2 is a recovery activity, focusing on construction of waste management centres (WMC). At least one WMC was to be constructed on each of the 74 islands to function as the island's initial facility for the separation and management of island waste. Component \#3 focuses again on recovery and concentrates on community education and awareness. It is about increasing the understanding and awareness of waste management practices; encouraging separation of waste, and proper use of the WMCs. This component includes such activities as training and follow-up visits or monitoring to ensure that the WMCs are maintained and used appropriately.

The original program was designed to complement the concurrent development of a national waste management strategy. The development and implementation of a national waste management policy was to be facilitated through the placement of a delegate in the Ministry (MEEW) and through direct support to its staff members while in the field. Integral to the Program was the Government commitment to remove and manage the accumulated waste and recyclables at the WMCs. Hence waste management centres were initially designed just to contain accumulated waste for a maximum period of three months prior to its collection and removal from an island.

\subsection{Program design: changes and implementation}

Based on the findings of regular monitoring visits, periodic reviews, and an external midterm review in September 2006, in November 2006, the initial exit strategy was revisited and revised in light of the change in the government's capacities. The program's long-term sustainability was brought into question as it became clear that the Government would not implement the collection system, including the final removal of waste and recycables from the islands because of their limited human and financial resources as stated in the MEEW letter to CRC dated 29 August 2006.

In order to address the practice of treating the WMC as a disposal site rather than a waste management site, a more aggressive focus on management, through the three Rs of Reduce, Reuse and Recycle, was promoted. Furthermore, interventions aimed at strengthening the community capacities in planning and implementing waste management practices from the household level to the final disposal were increased. The revised strategy combined safe burning practices, composting and community-initiated collection programs. Collection programs targeted the removal of non-combustible and non-compostable waste only and were conceived as a cost-sharing network with other islands. Equipment sharing was also envisaged; such as can crushers to reduce overall waste volumes, hence removal costs. Community mobilization, which had been a minor component in the initial program design, subsequently had to be integrated throughout the project cycle. It proved to be one of the key components in the success factors.

The program was initially designed as a basic recovery program to be accomplished within a limited timeframe; risk analyses included reconstruction- 
related price inflation and pressures for quick implementation from donors, beneficiaries and the GoM. It did not include a detailed analysis of partnerrelated risk factors. It should also be noted that neither the Australian Red Cross (ARC) nor the Canadian Red Cross (CRCS) societies had had previous program experience working in the Maldives, which in itself was an unidentified risk factor.

Consequently, ARC and CRCS learned that the community capacity assessment which had been undertaken during the initial design phase would have benefited significantly from a clearer understanding of Maldivian governance systems at both the island and atoll levels; particularly the decisionmaking processes and intergovernmental relations and the decision making authority of local and national authorities [8]. In addition to other problems, the program missed an opportunity to garner support for effective program implementation by not engaging the Ministry of Atolls Development in the early design and implementation stages. Once the need for change had been identified, changes had to be developed on the run; ultimately, some of the required major changes could not be undertaken or implemented in an optimal manner.

The Completion Report of the first phase highlighted the fact that implementation of the community development aspect was not optimized with regard to time, depth, and reach of community consultations and mobilizations [8]. Further, interventions to strengthen potential alternate solutions (to the government) in terms of final and sustainable waste removal from the islands could not be fully addressed (such as, the identification and promotion a successful self-reliant community waste management example as a role model to counter the belief about community versus government responsibilities). Likewise, while the program encouraged the community to explore options for final waste removal (e.g., resort partnerships, coordination with other islands in the atoll) stronger technical and advocacy support was not feasible.

\subsection{Phase 2 and implementation}

The second phase strategy relied on partnership with the MEEW based on the rationale that it would increase MEEW involvement and ownership in the community mobilization aspects of the program. This second phase's objectives were to improve waste-management practices at the community level through (a) the secondment of a community mobilization-specialist to the ERC, (b) the engagement of a training and awareness-raising specialist to develop educational tools; and (c) the training of ERC staff to implement public education and awareness programs [10]. The agreement was signed between the MEEW and CRC only with the financial support from Canadian International Development Agency or CIDA. It was implemented from March 2008 to June 2009 and focused on 23 islands, which were selected because of their good waste management practices at the end of the first phase of the program.

However, by the end of the program, only the first objective set out in the MEEW/EPA and CRC agreement was fully attained [10]. Following the signing of the agreement, the capacity of MEEW was subsequently weakened during a restructuring in which it became the Ministry of Housing, Transport and 
Environment in November 2008. The ERC was also restructured and renamed the Environmental Protection Agency (EPA). These changes created uncertainty among EPA personnel vis-à-vis individual roles and responsibilities, as well as the approval process for program activities, and ultimately accountability to EPA partners, including the CRC program. Consequently, the waste management practices of the island communities have not been fully reinforced at the end of the first phase of the program.

\section{Program outcomes}

\subsection{Cleanup of the islands}

Cleanup was undertaken and completed on 74 islands, mainly by contractors, except in two islands where the communities used local labour (GA. Nilandhoo and S. Meedhoo) [8]. Over $37,000 \mathrm{~m}^{3}$ of potentially dangerous waste was cleared: enough to fill some 2000 garbage trucks.

\subsection{Construction and use of the waste management centres}

ARC/CRC established 79 WMCs on 74 islands in 77 communities with the size and/or number of facilities matched to the specific island situations. Relevant reports estimated that about $70 \%$ of the WMCs were being used, but only $5 \%$ were used correctly $[7,11]$.

\subsection{Community education and awareness}

ARC/CRCS completed individual trainings for each of the 77 communities; in total 1,470 island representatives. An additional 2,027 students participated in the waste education sessions. Of the total participants, $57 \%$ were female. By mid-May 2009, during the implementation of the second phase, the concept of the Polluter Pays Principle or "PPP" had been introduced. PPP is one of the key components in a national solid waste management policy; it establishes and promotes community responsibility for the waste community members produce, shifting responsibility for dealing with waste away from governments to those producing it.

Monitoring visits throughout the implementation of the program and other final and evaluation reports $[7,11]$ found that community members demonstrated fair to good knowledge of waste management (e.g., awareness of hazardous waste, the link between waste and health, awareness about the need to deal with waste, etc.). The heightened level of awareness created by the program was illustrated by the fact that some communities, when approached by UNDP with a livelihood program, expressed a desire to do something related to waste management.

\subsection{Changes in behaviours and practices}

The evaluation [11] confirmed that the Program have changed their waste management practices. This includes taking waste to designated areas and a 
reduction in ocean dumping or buying of metals and plastics, and the use of multiple dump sites to fewer sites. In the majority of the islands metal cans are separated and in many locations crushed for transport [11]. Of the communities who are employing appropriate waste management practices there are some that have reverted back to less ideal waste disposal but keep separating burnable and non-burnable.

The EPA report stated that five of the 23 islands had the financial resources to undertake their own waste management and further five, after information sessions, indicated that they were favourable to the idea of PPP [7]. The final evaluation also reported an increased willingness for people to pay for their own waste management through PPP [11].

\subsection{Health and disease}

During the program duration, most communities reported improvements to health as one of the more common positive benefits of improved waste management practices. However, poor waste management practices (e.g., failure to flatten metal cans) and the absence of final removal of the accumulated metal and plastic has led to some WMCs providing ideal environments for mosquito breeding (e.g., standing freshwater in uncrushed cans) or focused environment for rodents [7, 11], although, the central facility limited the spread of these vectors around the island compared to the previous practices of multiple dumpsites which increased the spread.

\subsection{Unintended outcomes}

In spite of the program's limited interventions targeting the government, the interventions encouraged the government to formulate a policy on waste management and facilitated communication about waste management between island and atoll government offices [8]; a practice that continues to date [11]. The fact that waste management has become one of the most relevant issues to the Maldivian government, as well as to island communities, was evidenced by the fact that it became one of the top three election platforms for the election of the President in 2008 and subsequent Councillors [11]. On Kendhoo Island, one of the election candidates removed the waste from the island to demonstrate their conviction to waste management in response to community concerns regarding sustainable waste management [7].

\subsection{Factors in sustainable waste management practices}

Throughout the program, a wide variation in the degree of existing waste management practices was noted. Ultimately, the primary reason that most islands have not implemented sound practices or reverted to the previous unsound practices is the lack of a final solution in terms of the ability to remove the waste from the islands [7].

Some key factors in the sustainability of the waste management practices are as follows $[7,11]$. 
- An active Women's Development Committee: All islands with effectively run waste management also had active WDCs.

- Good coordination between an island's three decision-making bodies - Island Development Committee, WDC and Island Office: In general, small-sized islands had better waste management practices; however, some smaller communities (in terms of actual island-size and population) did not mirror this pattern due to poor coordination among the three decision-making bodies.

- Enabling island leadership without micromanagement. Providing leadership and empowerment for the WDC, who are responsible for waste management in the islands, thus had a positive impact on waste management practices.

- Sense of pride, competitiveness, volunteerism: On the islands where communities had a stronger sense of volunteerism, pride of their islands reputation and sense of competitiveness with other islands, there was a greater willingness to keep the islands clean.

\section{Lessons learned from applying the LRRD approaches in the program}

\subsection{LRRD approaches used by the program}

The program linked recovery, relief and development, but was also implemented under conditions that were both difficult and fluid: (a) post-disaster recovery, (b) political instability, (c) limited GoM capacity at the national and local levels, (d) limited community experience with participatory approaches, and (e) unrealistic community expectations vis-à-vis public services (i.e., who should pay). The most significant impact on the program emanated from, the conflict between the government and the communities regarding their opposing perceptions of who should ultimately be responsible for waste management costs.

Initially, the relief and recovery program attempted to bridge the link between relief and development by building capacity of the community (i.e., community education and follow-up visits) and local institutions (i.e., the secondment of personnel to MEEW). Once the GoM made its position clear about its inability to support regular removal of waste from the islands, the program was refocused to strengthen (a) community mobilization, and (b) community capacity for planning. In addition, it redefined exit strategies aimed at instilling a sense of ownership in the former MEEW for the community mobilization aspect of the program.

In a post-disaster or post-conflict context, humanitarian agencies frequently have to operate in a new country where they have no previous project or program experiences, hence, are less familiar with the socio-political dynamics. This situation is often compounded by time constraints: the need to response quickly. Both factors impacted on the ARC/CRC program. Furthermore, pressure from the various stakeholders in the early recovery phase to expedite the implementation phase also led to a less than optimal assessment in the design 
phase. The program applied rigorous oversight of the expected results through follow-up visits, routine monitoring, a mid-term review and other internal reviews; these contributed to the ongoing fine-tuning of the initial program design.

In the recovery context, frequent and regular oversight is essential; such practice assists in the ongoing fine-tuning of the initial design, an inevitable factor when an agency works in a country where the socio-political context is not fully familiar and where the community-related success factors and variables are not immediately evident or well understood.

\subsection{Stronger intervention to build community self-reliance at early phase}

The conflict over government versus community-level responsibility for waste management, posed significant problems throughout the program's implementation. Today there may, feasibly, be greater opportunity in terms of the communities' willingness to mobilize their own resources for waste management $[7,11]$. This increased openness can, in all likelihood, be attributed to the government's clarified stance vis-à-vis the communities' ownership and responsibility for waste management practices.

The program attempted to instil a greater sense of self-reliance half-way through the program; unfortunately, given the timing, a strong intervention was not possible: such as using islands with good practices as role models, more direct technical or advocacy and empowerment support to realize potential solutions for the final removal (e.g., resort partnerships, coordination with other islands in the atoll), etc.

Lessons learned from the program also suggest that within the fast-paced recovery context, it is extremely difficult, if not impossible, to make major changes to a program's design. Thus, it remains prudent to integrate a strong component for building community self-reliance into the program from the outset or, as early as possible, once the likelihood that it will be critical to the program's outcome and sustainability becomes evident. This will also serve as a form of risk management mitigation; particularly in the recovery context, where the government, partner agencies or humanitarian organizations may have overcommitted themselves due to conflicting expectations and pressures from different fronts [12], or where altered circumstance prevent one partner from meeting the expected commitments.

\subsection{Adequate capacity assessment and risk management}

With regard to working with local partners and communities as the LRRD approach, the program underscored the importance of having a good understanding of the following issues during a capacity assessment in the design phase.

(a) The local and national governance issues and procedures, both at the island and atoll level, as well as the decision-making process and the power of local and national authorities to follow through on commitments [8]. 
(b) The role of local institutions in view of sustaining the waste management practices; in this case, the WDC, the institution traditionally responsible for waste management on the island (its capacities were not fully utilised and empowered in the program) [7].

(c) The dynamics of volunteerism and pride within the targeted communities and a sense of competitiveness among islands.

The above information is critical to guide decision about selection of implementing partners - local institution (e.g., the WDCs as the duty bearer) and communities (characteristics) - as well as the types of capacity building undertakings employed for the institutions and the targeted communities. Choosing a local implementing partner for the exit strategy would also have benefited from a more comprehensive assessment of institutional capacities (e.g., power and accountability), major influential external factors (e.g., political instability), and required risk-mitigation measures to fall back on in the event that a partner was unable to deliver on its commitment, especially given the program's short time-frame.

Taking all these findings into account, within the recovery context, it remains critical that a thorough assessment of local institutional capacities, the targeted communities' decision-making and governance systems be undertaken, as well as a comprehensive risk assessment of potential implementing partners (design phase as well as in the exit strategy).

\section{Conclusions and lessons learned}

In summary, the experiences of the $\mathrm{ARC} / \mathrm{CRCS}$ waste management program demonstrate that it is possible to effect major changes within large dispersed populations in terms of waste management awareness, knowledge and practices within a relatively short period of time (2005 to 2007). Some changes can, because of the characteristics of community and local institutions, be sustained in spite of the inability or less-than-optimal interventions to address the root cause of problematic sustainability issues (i.e., regular removal of waste).

In terms of lessons learned for LRRD for future application within a similar context (government versus community responsibility, as well as limited timeframe), the following approaches should be considered.

- Conduct adequate and comprehensive capacity assessments of the targeted communities and local institutions in the design and exit strategy development phases or as early as possible.

- Integrate a strong and comprehensive community self-reliance intervention into the recovery program at the outset, even where the targeted community has only limited exposure to participatory approaches. Irrespective of government inputs, a self-reliant community is often critical to long-term sustainability.

- Be rigorous (a) in undertaking a risk assessment of potential implementing partners (including potential destabilizing socio-political factors and institutional accountability), and (b) in identifying and 
selecting relevant measures to mitigate the likelihood that implementing partners are unable to fully deliver on their commitments.

- Closely monitor and review progress; it is particularly critical where the context and key factors impacting on a successful outcome are not fully understood at the outset and/or are subject to volatile or fluid situations. Close monitoring will enable the application of timely, well-design modifications.

\section{References}

[1] Buchanan-Smith, M. \& Fabbri, P., Linking relief, rehabilitation and development: A review of the debate, 2005, www.tsunamievaluation.org/NR/...9EF5.../lrrd_review_debate.pdf

[2] Buttner, M., Concept paper: Linking relief, rehabilitation and development, 2008,www.disastergovernance.net/RTB_Concept_Paper_draft_martin_web.

[3] Campanaro, G., Hepburn, D., Kowalska, M., and Wang, A., Development relief: the European perspective, 2002, www.reliefweb.int/rw/lib.nsf /db900SID/LGEL-5J2LMH?

[4] Maldives from wikipedia, the free encyclopedia, en.wikipedia.org/wiki /Maldives

[5] The power and interest news report/PINR, Growing signs of unrest in the Maldives, 2005, http://www.minivannews.com/politics_detail.php?id=1142

[6] The World Bank, County Assistance Strategy for the Republic of Maldives FY08-FY12, Report No. 41400-MV, 2007, siteresources.worldbank.org/... /Resources/.../MaldivesCAS2008.pdf

[7] The Environmental Protection Agency/EPA of the Maldives. Communitybased waste management project: Final report, internal document submitted to CIDA, June 2009.

[8] Australian Red Cross and Canadian Red Cross, Tsunami debris and waste management program: Completion report - Phase one May 2005 to June 2007, internal document, 2008.

[9] Asian Development Bank, Maldives: Environment assessment, 2007, www.adb.org/.../Assessments/...Environmental/.../EnvironmentAssessment. pdf

[10] Canadian Red Cross, Tsunami debris and waste management program:: Final report - Phase two March 2008 to June 2009, internal document submitted to CIDA, 2009.

[11] Van Ham, M. Personal communication, June, July and August 2009. SYLVIS Environmental, Vancouver, Canada.

[12] Christoplos, I., and $\mathrm{Wu}, \mathrm{T} .$, Linking relief, rehabilitation and development (LRRD) \& social protection - Lessons from the Early Tsunami Response in Aceh. First International Conference on Aceh and Indian Ocean Studies, 2007, www.ari.nus.edu.sg/docs\%5CAceh-project\%5Cfull-papers\%5Caceh _fp_ianchristoplostreenawu.pdf 